\title{
Review of Pulsed Reduced Dose Rate Re-irradiation for Recurrent Tumors
}

Kevin Rogacki ${ }^{1}$, Samuel T. Chao ${ }^{2}$, Jennifer Yu $^{2}$, Andrew Godley ${ }^{2}$, Eshan Balagamwala ${ }^{2}$, John H. Suh ${ }^{2}$ and Erin S. Murphy ${ }^{*}$

${ }^{1}$ School of Medicine, Case Western Reserve University, Cleveland, Ohio, USA

${ }^{2}$ Department of Radiation Oncology, Cleveland Clinic, Cleveland, Ohio, USA

*Corresponding author: Erin Murphy, Department of Radiation Oncology, Cleveland Clinic, Cleveland, Ohio, USA; Email: murphye3@ccf.org

Received date: March 22, 2018; Accepted date: May 09, 2018; Published date: May 14, 2018

Copyright: ( 2018 Rogacki K, et al. This is an open-access article distributed under the terms of the Creative Commons Attribution License, which permits unrestricted use, distribution, and reproduction in any medium, provided the original author and source are credited.

\begin{abstract}
Pulsed Reduced Dose Rate (PRDR) is an external beam re-irradiation technique that may be appropriate for recurrent tumors in patients who have previously undergone radiation treatment. PRDR is thought to effectively target dividing neoplastic cells that display Low-Dose Hyper-Radiosensitivity (LDHRS) while permitting sub-lethal damage repair in non-proliferating normal tissues. To date, only a few case reports and several retrospective studies have reported on efficacy after PRDR retreatment across several disease sites, including CNS, breast, and nasopharyngeal tumors. In this article, we review available publications of PRDR re-irradiation in patients. Taken together, this research demonstrates that PRDR offers a treatment option for large volume recurrent disease at previously irradiated sites. More research is needed to establish therapeutic benefit and late adverse effects for each disease site.
\end{abstract}

Keywords: PRDR; PLDR; Re-irradiation; Reduced dose-rate; Recurrence; Radiotherapy; Cancer

Abbreviations: ATM: Ataxia Telangiectasia-Mutated; $\mathrm{H}$ and $\mathrm{N}$ : Head and Neck; IDRE: Inverse Dose Rate Effect; IRR: Increased Radio Resistance; LD-FRT: Low-Dose Fractionated Radiotherapy; LDHRS: Low-Dose Hyper-Radiosensitivity; PRDR: Pulsed Reduced Dose Rate; SLDR: Semicontinuous Low-Dose-Rate Teletherapy; SRS: Stereotactic Radiosurgery; WBRT: Whole Brain Radiation Therapy.

\section{Introduction}

Recurrent cancer after initial standard treatment is devastating for patients and physicians alike. In particular, treatment options following recurrence are often ill defined, sometimes with minimal data to support one approach over another. Moreover, utilization of reirradiation to treat recurrent cancer is frequently avoided due to concerns for exceeding normal tissue tolerances in the previous treatment area. Finally, re-irradiation is often employed in the palliative setting and less than definitive radiation doses are used. Therefore, data about tumor control following re-irradiation is often lacking.

Pulsed-Reduced Dose Rate (PRDR) is a re-irradiation technique that potentially overcomes volume and dose limitations in the setting of recurrent tumors. Tomé and Howard proposed a pulsed radiation strategy in glioma cell lines that exhibit Low-Dose HyperRadiosensitivity (LDHRS) [1]. In their analysis, models of glioma cell survival after low-dose, pulsed irradiation predicted greater tumor control than with standard dose-rates. In addition, their model predicted enhanced normal tissue repair as a result of longer treatment times inherent to PRDR.

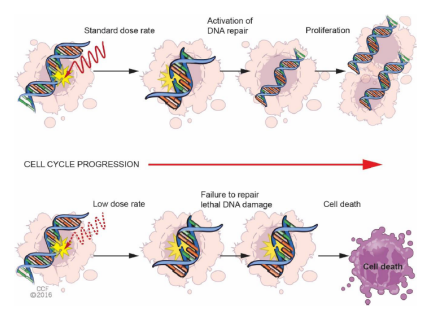

Figure 1. Schematic of low-dose hyper-radio-sensitivity in the context of pulsed reduced dose rate re-irradiation. Above-standard dose rates activate DNA repair mechanisms in irradiated tumor cells via increased radio-resistance, permitting repair of lethal DNA damage prior to cell division. Below-pulsed low dose rates lead to increased DNA damage in malignant cells displaying low-dose hyper-radio-sensitivity through failure to activate induced radioresistance. Treatment pulses fail to achieve the theoretical dose threshold to initiate increased radio-resistance or DNA damage repair.

Low-dose hyper-radiosensitivity is a radiobiological phenomenon whereby cells display higher sensitivity to lower doses of radiation than is expected from the linear quadratic model of cell survival. It has been demonstrated in vitro with doses $<1$ Gy [2-5]. It is thought that low dose radiation fails to activate DNA damage repair mechanisms that would otherwise halt progression through the cell cycle and protect irradiated cells from radiation induced cell death, a process known as Increased Radioresistance (IRR) (Figure 1). Specifically, cells that are irradiated above a threshold dose while in the G2 phase of the cell cycle will arrest at the G2 early checkpoint prior to mitosis in order to undergo DNA damage repair, leading to enrichment in this phase $[6,7]$. Molecularly, the arrest of cells in this checkpoint is Ataxia Telangiectasia-Mutated (ATM) dependent; a kinase known to be involved in activation of DNA repair [8]. Thus kinases like ATM may 
also regulate the transition of cellular response to radiation therapy from LDHRS at low doses to IRR at higher doses. These same mechanisms may also be implicated in the Inverse Dose Rate Effect (IDRE), a similar phenomenon of decreased cell survival over a range of low dose rates compared to high dose rates [9-14].

Concerning normal tissue, it is thought that a pulsed radiation delivery strategy preferentially sensitizes tumor cells displaying LDHRS to ionizing radiation to a greater extent than surrounding normal tissues, but only if the surrounding normal tissues do not exhibit LDHRS. Moreover, slowly proliferating normal tissues may be relatively insensitive to low-dose rate irradiation as more sub-lethal damage is repaired prior to cell division than in malignant cells during a protracted treatment session.

In this article, we survey the available literature for PRDR reirradiation in patients with recurrent tumors (Table 1).

\begin{tabular}{|c|c|c|c|c|c|c|c|}
\hline Study & $\mathbf{N}$ & Tumor type & PRDR dose & $\begin{array}{l}\text { Cumulative } \\
\text { dose }\end{array}$ & $\begin{array}{l}\text { PRDR Treatment } \\
\text { volume }\end{array}$ & Time to PRDR & Survival after PRDR \\
\hline Cannon & 1 & $\begin{array}{l}\text { Grade II to Grade IV } \\
\text { glioma }\end{array}$ & 50 Gy & $104 \mathrm{~Gy}$ & $\begin{array}{lr}\text { Treatment } & \text { volume } \\
\text { encompassed } & \text { of } \\
\text { region } & \text { with } \\
\text { recurrence } \\
\text { opposed fields }\end{array}$ & 3.5 y (from initial RT) & $\begin{array}{l}6 \text { months from completion } \\
\text { of PRDR }\end{array}$ \\
\hline Richards & 17 & Breast & $\begin{array}{l}\text { Median=54 Gy; } \\
\text { Range }=40-66 \\
\text { Gy }\end{array}$ & $\begin{array}{l}\text { Median=110 Gy; } \\
\text { Range=80-236 Gy }\end{array}$ & $\begin{array}{l}\text { Median }=2,084 \mathrm{~cm}^{3} ; \\
\text { Range }=843-7,881 \\
\mathrm{~cm}^{3}\end{array}$ & $\begin{array}{lr}\text { Median=58 } & \text { months; } \\
\text { Range }=19-213 & \text { months } \\
\text { (from initial diagnosis) }\end{array}$ & Median=23 months \\
\hline Adkison & 103 & Glioma & $\begin{array}{l}\text { Median=50 Gy; } \\
\text { Range=20-60 } \\
\text { Gy }\end{array}$ & Average $=106.8 \mathrm{~Gy}$ & $\begin{array}{l}\text { Mean treatment } \\
\text { volume }=403.5 \quad \pm \\
189.4 \mathrm{~cm}^{3}\end{array}$ & $\begin{array}{l}\text { Median=14 months (from } \\
\text { initial RT) }\end{array}$ & $\begin{array}{l}\text { Median=11.4 months ( } R: \\
1-33.8) \text { for low-Grade; } \\
\text { Median=5.1 months (R: } \\
1-48.4) \text { for Grade } 4\end{array}$ \\
\hline Guang-Hui & 1 & $\begin{array}{l}\text { Nasopharyngeal } \\
\text { carcinoma }\end{array}$ & 70 Gy & $\begin{array}{l}180-200 \text { Gy to } \\
\text { lymph nodes }\end{array}$ & $\begin{array}{l}5.5 \mathrm{~cm} \text { metastatic } \\
\text { lymph node in } \\
\text { greatest dimension }\end{array}$ & $\begin{array}{lcc}7.3 & y \\
\text { diagnosis } & \text { from initial }\end{array}$ & Not reported \\
\hline Guang-Hui & 1 & $\begin{array}{l}\text { NSCLC metastasis to } \\
\text { brain }\end{array}$ & $60 \mathrm{~Gy}$ & $\begin{array}{l}162 \text { Gy to } \\
\text { metastatic lesion }\end{array}$ & Not reported & $\begin{array}{l}1 \mathrm{y} \text { and } 7 \text { months from } \\
\text { initial RT }\end{array}$ & Not reported \\
\hline Mohindra & 5 & Ependymoma & $\begin{array}{l}\text { Median=40 Gy; } \\
\text { Range }=30-54 \\
\text { Gy }\end{array}$ & $\begin{array}{l}\text { Median=105.2 Gy; } \\
\text { Range=90-162.4 } \\
\text { Gy }\end{array}$ & $\begin{array}{l}\text { 2D spinal portal: } \\
\text { Mean spinal portal } \\
\text { area }=348 \mathrm{~cm}^{2}\end{array}$ & $\begin{array}{lr}\text { Median=58 } & \text { months; } \\
\text { Range=32-212 } & \text { months } \\
\text { (from initial RT) } & \end{array}$ & $\begin{array}{l}60 \% \text { estimated } 4 \text { y survival } \\
\text { since PRDR }\end{array}$ \\
\hline Magnuson & 23 & Grade IV Glioma & $54 \mathrm{~Gy}$ & Median=114 Gy & $\begin{array}{l}\text { Median } \quad P T V=424 \\
\mathrm{~cm}^{3} ; \\
\text { Range }=74-776 \mathrm{~cm}^{3}\end{array}$ & $\begin{array}{lr}\text { Median=11.8 } & \text { months; } \\
\text { Range }=6.8-36.8 & \text { months } \\
\text { (from initial RT) } & \end{array}$ & $\begin{array}{l}\text { Median }=6.9 \quad \text { months; } \\
\text { Range }=2.7-12 \text { months }\end{array}$ \\
\hline Murphy & 24 & CNS (21 Glioma) & $\begin{array}{l}\text { Median=54 Gy; } \\
\text { Range=38-60 } \\
\text { Gy }\end{array}$ & $\begin{array}{l}\text { Median=113.7 Gy; } \\
\text { Range=76-120 Gy }\end{array}$ & $\begin{array}{l}\text { Mean PTV }=369.2 \pm \\
178 \mathrm{~cm}^{3}\end{array}$ & $\begin{array}{l}\text { Median=48.1 months; } \\
\text { Range=16.5-387.7 } \\
\text { months (from initial RT) }\end{array}$ & $\begin{array}{l}\text { Median }=8.7 \quad \text { months; } \\
\text { Range=1.2-28.5 months }\end{array}$ \\
\hline Yan & 9 & $\begin{array}{l}\text { Glioma, } \mathrm{H} \text { and } \mathrm{N}, \\
\text { lung, esophageal, } \\
\text { colorectal, } \\
\text { chondrosarcoma }\end{array}$ & $\begin{array}{l}\text { Median=50; } \\
\text { Range=48-60 } \\
\text { Gy }\end{array}$ & $\begin{array}{l}\text { Median=110 Gy; } \\
\text { Range=104-166 Gy }\end{array}$ & Not reported & $\begin{array}{lr}\text { Median=36 } & \text { months; } \\
\text { Range=22-168 } & \text { months } \\
\text { (from initial RT) } & \end{array}$ & $\begin{array}{l}76 \% \text { at } 6 \text {-months and } 69 \% \\
\text { at } 1-y \text { for entire cohort of } \\
22 \text { patients (not only re- } \\
\text { irradiated patients) }\end{array}$ \\
\hline
\end{tabular}

Table 1. Studies and case reports of PRDR for recurrent tumors.

\section{Methods}

PubMed was searched for the terms "pulsed reduced dose rate" and "pulsed low dose rate." Of 444 results, eight articles evaluated retreatment of recurrent tumors with pulsed reduced dose rate irradiation in patients.

\section{PRDR for recurrent glioma}

Cannon et al. reported the first patient to undergo PRDR for treatment of recurrent glioma [15]. A $37 \mathrm{y}$-old male patient was initially diagnosed with WHO Grade II astrocytoma and underwent partial resection followed by 54 Gy in 1.8 Gy fractions of definitive radiation treatment. Upon progression three years later, the patient had a near total resection and received temozolomide for his tumor which had transformed to a WHO Grade IV, glioblastoma. His response to treatment was minimal and due to a lack of therapy options in the setting of prior radiotherapy, the patient was offered treatment with PRDR. Using a pulsed irradiation strategy, he received $50 \mathrm{~Gy}$ delivered in 25 daily fractions of $2.0 \mathrm{~Gy}$ at an apparent dose rate of $0.0667 \mathrm{~Gy} / \mathrm{min}$, for a cumulative total of $104 \mathrm{~Gy}$. Notably, the patient's weakness and seizure activity improved. MRI also demonstrated regression of nodular enhancement and improvement in mass effect. While not curative, PRDR demonstrated a potential treatment option in the setting of failed standard therapy.

Adkison et al. has performed the largest retrospective review of PRDR [16]. In this study, outcomes of 103 patients who underwent re- 
irradiation for recurrent glioma are reported. Patients received a median of 50 Gy in 1.8-2.0 Gy fractions at an apparent dose rate of $0.0667 \mathrm{~Gy} / \mathrm{min}$. For the entire cohort of patients, median survival after retreatment was 5.8 months with a median interval of 14 months from initial radiotherapy to PRDR. Histologic Grade at initial diagnosis, age at initial diagnosis and undergoing a second surgical intervention were significant predictors of survival. Patients with low Grade tumors had a significantly longer median overall survival of 11.4 months vs. patients with Grade 3 and Grade 4 tumors (5.6 and 5.1 months median overall survival, respectively). In addition, patients receiving $P R D R>14$ months from initial therapy had a greater overall survival than patients with a shorter interval from initial therapy to retreatment $(28 \mathrm{vs} .21$ weeks). Previous therapies such as gross vs. subtotal initial resection and systemic therapies (including temozolomide for Grade 4 patients) did not influence survival after PRDR. Notably, PRDR permitted large retreatment volumes with mean treatment volume of $403.5 \pm 189.4$ $\mathrm{cm}^{3}$ without apparent significant toxicity.

Magnuson et al. also evaluated PRDR after failure on bevacizumab for recurrent disease [17]. In this study, 23 patients with glioblastoma were initially treated with standard radiochemotherapy and had a median PFS of 6.5 months. Following initial recurrence, patients received bevacizumab therapy for a median PFS of 3.7 months. Upon bevacizumab failure, patients underwent PRDR to a dose of 54 Gy in 27 fractions to a median PTV of $424 \mathrm{~cm}^{3}$ along with 2 cycles of concurrent bevacizumab to prevent radiation necrosis. Median overall survival after progression on bevacizumab was 6.9 months (6 month OS of 65\%). This compared favorably against historical controls (median OS of 3.8 months). Importantly, however, the authors note a study by Cabrera et al. that suggests that SRS may offer superior OS for small-volume recurrent disease (median OS of 14.4 months) [18]. Therefore, recurrent tumor size is an important factor when considering re-irradiation techniques, and PRDR is most appropriate for large volume lesions.

In a retrospective series by Murphy et al. 24 heavily pre-treated patients with recurrent CNS tumors were offered IMRT-based PRDR to a median prescription dose of 54 Gy to a mean planning target volume (PTV) of $369 \mathrm{~cm}^{3}$ [19]. The median PFS from initiation of PRDR to progression on follow-up imaging was 3.1 months with a 6month PFS of $30.9 \%$. The median overall survival from PRDR was 8.7 months, with 6 and 12-month overall survival estimates of $70.8 \%$ and $31.2 \%$, respectively. When only glioma patients were included in the survival analysis $(n=21)$, median overall survival was 9.1 months postPRDR. The majority of toxicities attributed to PRDR were Grade 1 or 2 according to CTCAE v4.03 criteria and were very similar in frequency to the patients' first course of radiotherapy. Fatigue, alopecia and dermatitis occurred in more than half of all patients while receiving treatment. Neurological adverse events occurring during or after PRDR included seizure, ataxia, encephalopathy, personality change, diplopia, headache, memory impairment, tinnitus, peripheral neuropathy and upper extremity weakness. Grade 4 adverse events included pulmonary embolism $(n=2)$, cerebral edema $(n=1)$ and dysphasia $(n=1)$.

\section{PRDR for recurrent ependymoma}

In a study by Mohindra et al. five patients with recurrent ependymoma underwent PRDR re-treatment during the course of their disease [20]. In total, eight PRDR treatments were delivered to two intracranial sites and six spinal locations at a median re-irradiation dose of $40 \mathrm{~Gy}$. Cumulative radiation doses per site ranged from 90
Gy-162.4 Gy due to repeated treatments with standard and PRDR radiation therapy at some sites. Radiation planning was performed with 2D fluoroscopic simulation techniques or 3D-conformal techniques with a mean portal area of $348 \mathrm{~cm}^{2}$ and median volume of $882 \mathrm{~cm}^{3}$ encompassed by the $50 \%$ isodose line, respectively. Following re-irradiation, post-PRDR PFS was $53.6 \%$ at $2 \mathrm{y}$ and $35.7 \%$ at $4 \mathrm{y}$, with median PFS of 34 months. Estimated OS was $60 \%$ at $4 y$ and $40 \%$ at 6 $y$, with estimated median survival of 64 months. No radio-necrosis was evident in reviewed post-PRDR MRI studies.

\section{PRDR for recurrent breast cancer}

PRDR has been evaluated in the setting of recurrent breast cancer [21]. In this study, 17 patients underwent PRDR re-irradiation to the chest well, axilla and/or supraclavicular region for loco-regional recurrence of breast cancer. All patients had previously received postmastectomy radiation treatment with a median prior dose of $60 \mathrm{~Gy}$. Patients were treated to a median PRDR dose of 54 Gy and a median treatment volume of $2,084 \mathrm{~cm}^{3}$. Eight patients received concurrent chemotherapy. 7 of these patients received capecitabine. After treatment, 15 patients had complete resolution of the loco-regional recurrence. The estimated 2-y local control rate was $92 \%$ at a median follow-up of 18 months. Grade 3 acute skin toxicity was noted in $23 \%$ of patients, as well as two patients with Grade 3 and Grade 4 nonhealing chest wall ulcers. Of 15 patients treated to the axilla and/or supraclavicular area, none experienced brachial plexopathy.

\section{PRDR for recurrent nasopharyngeal carcinoma}

A case report by Guang et al. detailed a complete response in a patient with recurrent poorly differentiated squamous cell carcinoma of the nasopharynx metastatic to a cervical lymph node after treatment with PRDR [22]. After an initial diagnosis of T2N2M0 tumor, the patient received 70 Gy delivered with a 3-field external beam radiotherapy plan to the gross tumor volume and a metastatic lymph node. At the same time, he also received $\geq 50$ Gy to the bilateral cervical lymphatics. The following year a $1.5 \mathrm{~cm}$ recurrence in a lymph node was found during routine surveillance, for which the patient declined treatment. 5 y later, he received an additional 60 Gy using three-dimensional conformation radiotherapy followed by surgical dissection for recurrent metastatic lymph nodes in the neck. This was followed by adjuvant chemotherapy with paclitaxel and cisplatin. Unfortunately, a second recurrence resistant to cisplatin/fluorouracil and cisplatin/paclitaxel systemic treatments was discovered a year later, for which the patient was treated with PRDR and concurrent cetuximab. PRDR was delivered to dose of $70 \mathrm{~Gy}$ in 35 daily fractions of 2.0 Gy. In total, the patient received up to 190 Gy to the $\mathrm{H}$ and $\mathrm{N}$ region and experienced Grade 1 acute skin toxicity and no significant late toxicity during PRDR treatment.

\section{PRDR for squamous cell lung carcinoma brain metastasis}

In another case report by Guang et al. PRDR was used to treat a metastatic lesion to the left occipital lobe in a patient with NSCLC [23]. After having initially received chemoradiaton to the left inferior lung and mediastinal lymph nodes for stage T2N3M0 squamous cell carcinoma, the patient received 40 Gy WBRT for multiple metastatic brain lesions with $20 \mathrm{~Gy}$ boost to a left occipital metastatic site. Due to persistence of this lesion, the patient received salvage SRS to 14 Gy in 4 fractions. Following subsequent recurrence, he received additional SRS to $28 \mathrm{~Gy}$ in 8 fractions with concurrent nimustine (ACNU). After the third recurrence, the patient refused surgery and was subsequently 
treated with 60 Gy PRDR in 30 fractions of 2.0 Gy for a total of $162 \mathrm{~Gy}$ to the left occipital lobe brain metastasis. Following PRDR, the patient had resolution of headache, vomiting and dizziness and continued to live independently with intact cognitive function, although he declined further diagnostic testing and treatment.

\section{PLDR in refractory malignancies}

More recently, 22 patients underwent pulse low dose rate reirradiation for recurrent cancers of various histologies as part of a single center experience [24]. All patients were treated with 10 fractions of $2 \mathrm{~Gy}$ at an effective dose rate of $0.0667 \mathrm{~Gy} / \mathrm{min}$; taking all patients together, the 1-y local-regional control rate was $40 \%$. The 6 month survival rate was $76 \%$ and $1-y$ survival rate was $69 \% .9$ of these patients underwent re-irradiation, including a patient with $\mathrm{H}$ and $\mathrm{N}$ cancer, two patients with lung cancer, two patients with glioma, two patients with esophageal cancer, one patient with colorectal cancer and another patient with chondrosarcoma. The time interval between initial radiotherapy and re-irradiation was 11-168 months, with cumulative doses between 104-166 Gy. Doses delivered by PLRD were between 48-60 Gy. For patients undergoing re-irradiation, toxicity was well tolerated. The patient with $\mathrm{H}$ and $\mathrm{N}$ cancer developed Grade 1 bone marrow suppression and Grade 2 stomatitis in the setting of concurrent chemo-radiation. One patient re-irradiated for lung cancer developed Grade 1 pneumonitis while receiving concurrent chemotherapy. Finally, the patient with recurrent glioma developed mild brain swelling. Of patients undergoing re-irradiation, three patients achieve partial remission, 5 patient's demonstrated stable disease and one patient developed progressive disease.

\section{Discussion}

Pulsed reduced dose rate is an external beam re-irradiation strategy to treat recurrent tumors while potentially limiting toxicity to surrounding normal tissues. To date, it has been studied most extensively in the setting of recurrent CNS tumors.

To achieve a low dose rate, a daily dose of $2 \mathrm{~Gy}$ is given in $0.2 \mathrm{~Gy}$ pulses separated by 3-min intervals, for an apparent dose rate of 0.0667 Gy/min. In doing so, Low-Dose Hyper-Radiosensitivity (LDHRS) occurs in susceptible malignant tissue by failing to activate DNA repair mechanisms active at conventional dose rates. In addition, surrounding normal tissues may be spared to a greater degree than cancerous tissues as DNA repair mechanisms are enhanced by longer treatment times-as long as these normal tissues do not themselves display LDHRS. Thus, PRDR may overcome volume and dose constraints in the re-irradiation setting.

Certainly, other radiotherapy tools including radiosurgery and stereotactic body radiotherapy are available in the retreatment setting. However, these tools have limited use when large tumor volumes require comprehensive retreatment and dose to normal critical structures is unavoidable.

In a notable example of low dose radiotherapy for recurrent tumors, Balducci et al. evaluated Low Dose Fractionated Radiotherapy (LDFRT) for treatment of recurrent GBM on the basis LDHRS and chemosensitization [25]. While distinct from PRDR, LD-FRT is a hyper-fractionation technique that may exploit LDHRS for therapeutic gain. Specifically, doses significantly below the LDHRS threshold of approximately $1 \mathrm{~Gy}$ are delivered in twice-daily treatments with concurrent chemotherapy. In this study, 32 patients received LD-FRT plus chemotherapy for recurrent disease that were previously treated at initial diagnosis by radiotherapy plus concomitant and sequential temozolomide. One of two regimens was employed as determined by time of recurrence relative to treatment with adjuvant temozolomide. Patients with progressive disease during adjuvant temozolomide received cisplatin (days $1,8,15$ ) and fotemustine (days 2, 9, 16) with 0.3 Gy twice daily concomitant radiotherapy on days 1-2, 8-9, 15-16, every $42 \mathrm{~d}$ for 2 cycles for a total dose of 7.2 Gy. Patients with progressive disease more than 4 months after the end of adjuvant temozolomide received a temozolomide re-challenge combined with LD-FRT 0.4 Gy twice daily over five consecutive days, every $28 \mathrm{~d}$ for 2 cycles for a total of $8 \mathrm{~Gy}$. There was a minimum of 6 -h between daily radiotherapy fractions, with chemotherapy given during this intrafraction interval. Patients were eligible to receive additional cycles of chemoradiation provided absence of progression on follow up imaging as well as tolerance of adverse effects. $65.6 \%$ of patients received LDFRT+temozolomide therapy and $34.4 \%$ of patients received LD-FRT +platinum/fotemustine. The median CTV was $49.01 \mathrm{~cm}^{3}$. In terms of results, one patient showed a complete response (3.1\%), 3 patients demonstrated a partial response $(9.4 \%), 8$ patients demonstrated stable disease for at least 8 weeks after the end of treatment (25\%), and 20 patients had disease progression (62.5\%). Median PFS was 5 months and median OS was 8 months. Patients with MGMT methylation demonstrated improved PFS and OS. On evaluation of toxicity, $9.4 \%$ of patients experienced Grade 3-4 hematological toxicities and no late adverse effects were observed over a median follow-up of 22.5 months. Taken together, this study represents an important investigation into whether a hyper-fractionated regimen represents a hitherto untapped potential for therapeutic gain clinically. However, it is admittedly difficult to say whether or not LDHRS underpins the clinical response seen in responding patients without in vitro assessment of patientspecific tumor LDHRS. Yet, it did demonstrate the feasibility and tolerability of hyper-fractionated radiotherapy regimens in the recurrent setting, at least at this smaller treated volume when compared to treatment volumes typically employed with PRDR.

In examining other low dose-rate radiation techniques for recurrent CNS tumors, PRDR compares well to interstitial iodine-125 brachytherapy. In a study by Kickingereder et al. 201 patients with inoperable primary and recurrent glioblastoma were treated with iodine-125 seeds to a median surface dose of $60 \mathrm{~Gy}$ at a median doserate of $6 \mathrm{cGy} / \mathrm{h}$ [26]. In addition, $90.3 \%$ of patients in the primary treatment group received external boost radiotherapy to a median dose of $25.2 \mathrm{~Gy}$. The median gross-tumor-volume was $17 \mathrm{~cm}^{3}$. Following implantation, there was a transient and permanent procedure-related morbidity rate of 7.5 and $2.0 \%$, respectively. Median OS was 10.5 months and PFS was 6.2 months, with no difference among primary vs. recurrent tumors. In addition, tumor volume was a significant risk factor for developing symptomatic peritumoral edema or radiationinduced changes, occurring in 4 patients in this study (mean GTV of $19.3 \mathrm{ml}$ in patients without changes $v s .28 .9 \mathrm{ml}$ with changes, $\mathrm{p}=0.03$ ).

In comparing interstitial brachytherapy to PRDR for high Grade glioma, it is clear that interstitial brachytherapy is best suited for small, well-circumscribed tumors. The initially smaller tumor treatment size in the study cited above may also explain the relatively favorable OS and PFS of interstitial iodine-125 brachytherapy when comparing it to currently available studies evaluating PRDR treatment of recurrent high Grade glioma. Furthermore, interstitial brachytherapy requires an invasive procedure, of which the risk of procedure related complications are small but not negligible. In this regard, PRDR delivered by EBRT allows patients who may not be surgical candidates to benefit from low dose rate radiation therapy. 
Page 5 of 6

PRDR is also an attractive alternative to very low dose rate EBRT because of the practical advantage of shorter treatment times. In a study completed by Siker et al. 22 patients with predominantly high Grade recurrent gliomas were treated with Semi-Continuous LowDose-Rate teletherapy (SLDR) using a modified cobalt-60 treatment unit [27]. A total dose of 30 to $35 \mathrm{~Gy}$ was given over $12 \mathrm{~d}$ at a dose rate of 40 to $50 \mathrm{cGy} / \mathrm{h}$ delivered in 6 to $8 \mathrm{~h} / \mathrm{d}$. The dose rate was chosen so as to recapitulate the inverse dose rate effect observed in some cell lines $[28,29]$. Overall survival after SLDR was $56 \%$ at 6 months, $28 \%$ at 1 y and $17 \%$ at $2 \mathrm{y}$. As evidenced by one patient needing to stop treatment due to discomfort because of treatment positioning and immobilization, the longer treatment time in SLDR is less tolerable. Thus, PRDR performs similarly to SLDR with significantly less time commitment to daily treatment sessions. Nevertheless, it is noted that the lower dose rates employed in SLDR may lead to improved late tissue toxicity effects when compared to PRDR. Yet, until survival for recurrent cancer improves substantially, we argue that any improvement in normal tissue tolerance that is achieved is not as significant a consideration when weighing the merits of SLDR against PRDR.

\section{Summary}

To date, reports and studies evaluating PRDR as a retreatment strategy for recurrent tumors have demonstrated palliative benefits when therapeutic options are limited. Furthermore, despite retreatment to large cumulative doses and often significant retreatment volumes, reported toxicity is acceptable. When comparing PRDR to other low dose and low dose rate re-irradiation strategies, PRDR demonstrates similar efficacy with the distinct advantages inherent to its non-invasive application, relatively compact treatment delivery time, as well as demonstrated tolerance for large treatment volumes. Yet, of the utility of PRDR remains controversial and not widely adapted for treatment of recurrent tumors considering existing limited evidence [30]. A valid criticism of PRDR as a re-irradiation technique is that current evidence comprises case reports and retrospective studies, often with limited patient numbers. In addition, most of these studies were not designed to evaluate outcomes such as late adverse effects, making it difficult to evaluate the theoretical advantage of improved normal tissue tolerance. Also, despite larger studies in the setting of recurrent CNS tumors, there are only a few small studies and case reports published for other sites, making extrapolations of the data tenuous at best. As a result, there is a need to carry out prospective studies or randomized trials using PRDR in the recurrent setting across disease sites. It will also be helpful to clarify the role of tumor LDHRS in vitro as a predictor of response to PRDR.

In conclusion, local tumor progression after prior radiation therapy represents a significant therapeutic challenge due to appropriate concern of unacceptable toxicity to surrounding normal tissues with additional radiation. Pulsed reduced dose rate is an irradiation strategy that may overcome the limitations of conventional radiation therapy in the setting of large volume recurrent tumor and provides a similar level of tumor control when compared to existing treatment options.

\section{Conflicts of Interest Statement}

The authors of this review article do not report any financial or personal conflicts of interest.

\section{Funding Sources}

This research did not receive any specific grant from funding agencies in the public, commercial, or not-for-profit sectors.

\section{Acknowledgement}

The authors of this review would like to acknowledge Beth Halasz in the Center for Medical Art and Photography at the Cleveland Clinic. In addition, the first author would like to acknowledge the support and mentorship of the Radiation Oncology Department at the Cleveland Clinic.

\section{References}

1. Tome WA, Howard SP (2006) On the possible increase in local tumour control probability for gliomas exhibiting low dose hyper-radiosensitivity using a pulsed schedule. Br J Radiol 80: 32-37.

2. Short SC, Mitchell SA, Boulton P, Woodcock M, Joiner MC (1999) The response of human glioma cell lines to low-dose radiation exposure. Int J Radiat Biol 75: 1341-1348.

3. Short SC, Kelly J, Mayes CR, Woodcock M, Joiner MC (2001) Low-dose hypersensitivity after fractionated low-dose irradiation in vitro. Int $\mathrm{J}$ Radiat Biol 77: 655-664.

4. Beauchesne PD, Bertrand S, Branche R (2003) Human malignant glioma cell lines are sensitive to low radiation doses. Int J Cancer 105: 33-40.

5. Short SC, Woodcock M, Marples B, Joiner MC (2003) Effects of cell cycle phase on low-dose hyper-radiosensitivity. Int J Radiat Biol 79: 99-105.

6. Xu B, Kim S, Lim D, Kastan MB (2002) Two molecularly distinct G(2)/M checkpoints are induced by ionizing irradiation. Mol Cell Biol 22: 1049-1059.

7. Krempler A, Deckbar D, Jeggo PA, Lobrich M (2007) An imperfect G2M checkpoint contributes to chromosome instability following irradiation of S and G2 phase cells. Cell Cycle 6: 1682-1686.

8. Krueger SA, Collis SJ, Joiner MC, Wilson GD, Marples B (2007) Transition in survival from low-dose hyper-radiosensitivity to increased radioresistance is independent of activation of ATM Ser1981 activity. Int J Radiat Oncol Biol Phys 69: 1262-1271.

9. Hall EJ, Brenner DJ (1991) The dose-rate effect revisited: radiobiological considerations of importance in radiotherapy. Int J Radiat Oncol Biol Phys 21: 1403-1414.

10. Joiner MC, Marples B, Lambin P, Short SC, Turesson I (2001) Low-dose hypersensitivity: Current status and possible mechanisms. Int J Radiat Oncol Biol Phys 49: 379-389.

11. Collis SJ, Schwaninger JM, Ntambi AJ (2004) Evasion of early cellular response mechanisms following low level radiation-induced DNA damage. J Biol Chem 279: 49624-49632.

12. Marples B, Wouters BG, Collis SJ, Chalmers AJ, Joiner MC (2004) Lowdose hyper-radiosensitivity: a consequence of ineffective cell cycle arrest of radiation-damaged G2-phase cells. Radiat Res 161: 247-255.

13. Marples B, Collis SJ (2008) Low-dose hyper-radiosensitivity: past, present, and future. Int J Radiat Oncol Biol Phys 70: 1310-1318.

14. Leonard BE (2007) Thresholds and transitions for activation of cellular radioprotective mechanisms - correlations between HRS/IRR and the "inverse" dose-rate effect. Int J Radiat Biol 83: 479-489.

15. Cannon GM, Tomé WA, Robins HI, Howard SP (2007) Pulsed reduced dose-rate radiotherapy: case report: a novel re-treatment strategy in the management of recurrent glioblastoma multiforme. J Neurooncol 83: 307-311.

16. Adkison JB, Tomé W, Seo S (2011) Re-irradiation of large-volume recurrent glioma with pulsed reduced-dose-rate radiotherapy. Int J Radiat Oncol 79: 835-841.

17. Magnuson W, Robins HI, Mohindra P, Howard S (2014) Large volume reirradiation as salvage therapy for glioblastoma after progression on bevacizumab. J Neurooncol 117: 133-139. 
Citation: Rogacki K, Chao ST, Yu J, Godley A, Balagamwala E, et al. (2018) Review of Pulsed Reduced Dose Rate Re-irradiation for Recurrent

Page 6 of 6

18. Cabrera AR, Cuneo KC, Desjardins A (2013) Concurrent stereotactic radiosurgery and bevacizumab in recurrent malignant gliomas: A prospective trial. Int J Radiat Oncol Biol Phys 86: 873-879.

19. Murphy ES, Rogacki K, Godley A (2017) Intensity modulated radiation therapy with pulsed reduced dose rate as a re-irradiation strategy for recurrent central nervous system tumors: An institutional series and literature review. Pract Radiation Oncol 7: 391-399.

20. Mohindra P, Robins IH, Tomé WA, Hayes L, Howard SP (2013) Widefield Pulsed Reduced Dose Rate Radiotherapy ( PRDR ) for Recurrent Ependymoma in Pediatric and Young Adult Patients. Anticancer Res 33: 2611-2618.

21. Richards GM, Tome WA, Robins HI (2009) Pulsed reduced dose-rate radiotherapy: a novel locoregional retreatment strategy for breast cancer recurrence in the previously irradiated chest wall, axilla, or supraclavicular region. Breast Cancer Res Treat 114: 307-313.

22. Li G, Zhu BO, Yang F, Ma C, Yang D (2012) Use of cetuximab in combination with pulsed reduced dose-rate radiotherapy in a patient with recurrence of nasopharyngeal carcinoma in the neck. Exp Ther Med 3: 869-872.

23. Li G, Liu Y, Tang J (2012) Pulsed reduced dose-rate radiotherapy as re irradiation for brain metastasis in a patient with lung squamous-celled carcinoma. Jpn J Clin Oncol 42: 856-860.
24. Yan J, Yang J, Yang Y (2018) Use of pulsed low-dose rate radiotherapy in refractory malignancies. Transl Oncol 11: 175-181.

25. Balducci M, Diletto B, Chiesa S (2014) Low-dose fractionated radiotherapy and concomitant chemotherapy for recurrent or progressive glioblastoma: Final report of a pilot study. Strahlentherapie und Onkol 190: 370-376.

26. Kickingereder P, Hamisch C, Suchorska B (2014) Low-dose rate stereotactic iodine-125 brachytherapy for the treatment of inoperable primary and recurrent glioblastoma: single-center experience with 201 cases. J Neurooncol 120: 615-623.

27. Siker ML, Firat SY, Mueller W, Krouwer H (2012) Semicontinuous lowdose-rate teletherapy for the treatment of recurrent glial brain tumors: final report of a phase I/II study. Int J Radiat Oncol 82: 765-772.

28. Mitchell JB, Bedford JS, Bailey SM (1979) Dose-rate effects in mammalian cells in culture III. Comparison of cell killing and cell proliferation during continuous irradiation for six different cell lines. Radiat Res 79: 537-551.

29. Mitchell JB, Bedford JS, Bailey SM (1979) Dose-rate effects in plateauphase cultures of S3 HeLa and V79 cells. Radiat Res 79: 552-567.

30. Ma C-MC, Luxton G, Orton CG (2011) Point/counterpoint: pulsed reduced dose rate radiation therapy is likely to become the treatment modality of choice for recurrent cancers. Med Phys 38: 4909-4911. 